\title{
Martha M. Roggenkamp, Edwin Woerdman (eds.): Legal design of carbon capture and storage, developments in the Netherlands from an international and EU perspective, energy and law, volume 10 \\ Intersentia, 2009, xxx +360 pp
}

\section{Jürgen G. Backhaus}

Published online: 29 January 2011

(C) Springer Science+Business Media, LLC 2011

Carbon capture and storage is an option recently added to the Kyoto Protocol and analyzed here by means of modern law and economics.

Martha Roggenkamp is a practising lawyer in Amsterdam and professor in Groningen while Edwin Woerdman is an economist and associate professor of law and economics at the Law School in Groningen, specializing in environmental economics.

The book is organized into four parts. The thirteen chapters deal, respectively with:

1. Introduction to the CCS chain: Technological and safety risks

2. Challenging complexities of CCS in public international law

3. CCS under the project-based Kyoto mechanisms

4. CCS in the European emissions trading scheme

5. EC competition law and the organisation of CCS

6. Environmental law and CCS in the EU and the impact on the Netherlands

7. Pipelines transporting $\mathrm{CO}_{2}$ from a public and private law perspective

8. Regulating underground storage of $\mathrm{CO}_{2}$

9. Post-injection liability for onshore $\mathrm{CO}_{2}$ storage

10. The concept of third party access applied to CCS

11. The role of the competent authority in regulating CCS

12. The law as a barrier or a tool for promoting CCS

13. Looking beyond the legal uncertainties of CCS

Focusing on the specific context of Dutch law and also considering the recent EU initiative on CCS, the authors discuss legal opportunities for and legal barriers to CCS.

\footnotetext{
J. G. Backhaus (凹)

Erfurt, Germany

e-mail: juergen.backhaus@uni-erfurt.de
} 